\title{
IEDITORIAL
}

\section{Medical emergency team interventions in patients with ST-segment elevation myocardial infarction in Poland: how to improve outcomes?}

\author{
Avinoam Shiran, Basheer Karkabi, Moshe Y. Flugelman
}

Department of Cardiovascular Medicine, Lady Davis Carmel Medical Center and the Rappaport Faculty of Medicine, Technion-Israel Institute of Technology, Haifa, Israel

RELATED ARTICLE

by Nadolny et al, see p. 292
Correspondence to:

Moshe Y. Flugelman, MD, Department of Cardiovascular Medicine, Lady Davis Carmel Medical Center and the Rappaport Faculty of Medicine, Technion-Israel Institute of Technology, 7 Michal, 34632 Haifa, Israel, phone: +97248250575, email: myf@technion.ac.il Received: March 30, 2020. Accepted: March 31, 2020. Published online: April 24, 2020 Kardiol Pol. 2020; 78 (4): 267-268 doi:10.33963/KP.15301 Copyright by the Author(s), 2020
Reperfusion in acute ST-segment elevation myocardial infarction (STEMI) has revolutionized cardiology and improved patient prognosis. " The realization that "time is muscle," together with advances in interventional cardiology, led to a dramatic reduction in in-hospital mortality and morbidity in patients with STEMI. This change required the reorganization of out-of-hospital emergency services, emergency room practices, and catheterization laboratory operation. ${ }^{2,3}$ Coordinating all medical professionals involved in the process became a centerpiece in the treatment of STEMI. Guidelines issued in accordance with large bodies of evidence set the door-to-balloon (D2B) time, ie, the time from hospital entry to balloon inflation in the culprit coronary lesion, to less than $90 \mathrm{~min}$, and preferably to less than $60 \mathrm{~min} .4,5$ However, in a study on patients with STEMI, who were candidates for primary percutaneous coronary intervention in the United States, mortality rates did not decrease despite a significant reduction in the D2B time. ${ }^{6}$ That study highlighted the key role of time to first medical contact and prehospital treatment. Since then, the focus in the treatment of STEMI has shifted from the D2B time to the total time of ischemia and to multistage treatment including various steps taken both outside and inside hospitals..$^{7-9}$ Based on the sequence of events, during the first medical contact, a 12-lead electrocardiogram (ECG) should be performed and STEMI should be diagnosed, either independently or with assistance. Once a diagnosis is established, the rapid transfer to the catheterization laboratory is crucial. The hospital team should be alerted at the earliest time possible. During transportation, heparin and antiplatelet therapy, mainly aspirin, should be administered, based on the extensive evidence that early treatment improves patient outcomes. ${ }^{10,11}$ In the hospital, the direct transfer to the catheterization laboratory and bypassing the emergency room shorten the D2B time. Finally, a transradial approach is recommended to reduce bleeding complications. ${ }^{8}$

Nadolny et $\mathrm{al}^{12}$ examined the prehospital management of patients with STEMI in Poland. They showed that 12-lead ECGs were performed during $98.6 \%$ of medical emergency team (MET) interventions and transmitted in $37.5 \%$ of the interventions. Although patients with STEMI represent a low proportion of the MET workload, the high rate of 12-lead ECGs performed attests to the high-quality work of METs. However, the relatively low rate of ECGs transmitted to the hospital should be improved. Transmitting 12-lead ECGs to the hospital can increase alertness and enable bypassing the emergency room. This can also reduce the rate of false activations of catheterization laboratory teams. ${ }^{13}$ It also would be of great interest to examine whether ECG transmission is associated with shorter D2B times.

Nadolny et $\mathrm{al}^{12}$ reported on administering dual antiplatelet therapy (DAPT) in $72.1 \%$ of the interventions reviewed. Clopidogrel was used in $49.7 \%$ of them, and ticagrelor in $25.1 \%$ $(P<0.001)$. A P2Y12 inhibitor was most often applied in the Wielkopolska (98.4\%) and least often in Silesia (40.34\%) provinces. The relevance of early antiplatelet therapy, using mainly aspirin, was shown in several studies. ${ }^{10,11}$ Benefits associated with the early administration of P2Y12 inhibitors are still inconclusive, though 


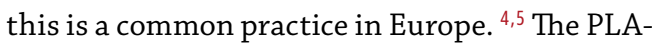
TO (Platelet Inhibition and Patient Outcomes) study showed that the use of ticagrelor was superior to that of clopidogrel, although the investigation was not conducted in a prehospital setting. Administering DAPT to patients without STEMI may be deleterious. Thus, it would be interesting to know how many patients of those diagnosed with STEMI by the METs actually had STEMI.

In general, quality improvement should begin with mapping the current situation. Specifically, geographical differences should be addressed with regard to rates of DAPT administration. In this respect, the nature of the study performed by Nadolny et $\mathrm{a}^{12}$ is of high importance, as shown in a study from our center and a study based on data from a national registry. ${ }^{14,15}$ It demonstrated that 12-lead ECGs were performed in almost all patients (but only in one-third of them, ECGs were transmitted to the hospital). The large geographical differences in treatment highlight the potential for improving rates of DAPT administration. Looking at the process timeline, transmitting ECGs to the hospital can increase the rates of DAPT administration after confirming the diagnosis of STEMI. Studies performed on a local and national scale, such as the study of Nadolny et al, ${ }^{12}$ are probably the best means of improving care in general and outcomes in patients with STEMI specifically. Thus, the authors should be congratulated on their study, which will inevitably lead to better care and outcomes in this patient population.

\section{ARTICLE INFORMATION}

DISCLAIMER The opinions expressed by the author are not necessarily those of the journal editors, Polish Cardiac Society, or publisher.

CONFLICT OF INTEREST None declared.

OPEN ACCESS This is an Open Access article distributed under the terms of the Creative Commons Attribution-NonCommercial-NoDerivatives $4.0 \mathrm{In}$ ternational License (CC BY-NC-ND 4.0), allowing third parties to download articles and share them with others, provided the original work is properly cited, not changed in any way, distributed under the same license, and used for noncommercial purposes only. For commercial use, please contact the journal office at kardiologiapolska@ptkardio.pl.

HOW TO CITE Shiran A, Karkabi B, Flugelman MY. Medical emergency team interventions in patients with ST-segment elevation myocardial infarction in Poland: how to improve outcomes? Kardiol Pol. 2020; 78: 267-268. doi:10.33963/ KP.15301

\section{REFERENCES}

1 Nabel EG, Braunwald E. A tale of coronary artery disease and myocardial infarction. N Engl J Med. 2012; 366: 54-63.

2 Bradley EH, Herrin J, Wang Y, et al. Strategies for reducing the door-to-balloon time in acute myocardial infarction. N Engl J Med. 2006; 355: 2308-2320.

3 Le May MR, Dionne R, Maloney], Poirier P. The role of paramedics in a primary PCI program for ST-elevation myocardial infarction. Prog Cardiovasc Dis. 2010; 53: 183-187.

4 Ibanez B, James S, Agewall S, et al. 2017 ESC guidelines for the management of acute myocardial infarction in patients presenting with ST-segment elevation. Eur Heart J. 2018; 39: 119-177.

5 Wong GC, Welsford M, Ainsworth C, et al. 2019 Canadian Cardiovascular Society/Canadian Association of Interventional Cardiology guidelines on the acute management of ST-elevation myocardial infarction: focused update on regionalization and reperfusion. Can J Cardiol. 2019; 352: 107-132.

6 Menees DS, Peterson ED, Wang Y, et al. Door-to-balloon time and mortality among patients undergoing primary PCI. N Engl J Med. 2013; 369: 901-909.
7 Alsamara M, Degheim G, Gholkar G, et al. Is symptom to balloon time a better predictor of outcomes in acute ST-segment elevation myocardial infarction than door to balloon time? Am J Cardiovasc Dis. 2018; 8: 43-47.

8 Huded CP, Kumar A, Johnson M, et al. Incremental prognostic value of guideline-directed medical therapy, transradial access, and door-to-balloon time on outcomes in ST-segment-elevation myocardial infarction. Circ Cardiovasc Interv. 2019; 12: e007101.

9 Foo CY, Andrianopoulos N, Brennan A, et al. Re-examining the effect of doorto balloon delay on STEMI outcomes in the context of unmeasured confounders: a retrospective cohort study. Sci Rep. 2019; 9:19978.

10 Barbash I, Freimark D, Gottlieb S, et al; Israeli Working Group on Intensive Cardiac Care, Israel Heart Society. Outcome of myocardial infarction in patients treated with aspirin is enhanced by pre-hospital administration. Cardiology. 2002; 98: 141-147.

11 Price MJ, Angiolillo DJ, Teirstein PS, et al. Platelet reactivity and cardiovascular outcomes after percutaneous coronary intervention: a time-dependent analysis of the Gauging Responsiveness with a Verify Now P2Y12 assay: Impact on Thrombosis and Safety (GRAVITAS) trial. Circulation. 2011; 124: 1132-1137.

12 Nadolny K, Ładny JR, Gałązkowski R, et al. Medical emergency team interventions in patients with ST-segment elevation myocardial infarction in Poland in 2018. Kardiol Pol. 2020; 78: 292-299.

13 Degheim G, Berry A, Zughaib M. False activation of the cardiac catheterization laboratory: the price to pay for shorter treatment delay. JRSM Cardiovasc Dis. 2019; 8: 2048004019836365

14 Karkabi B, Jaffe R, Halon DA, et al. An intervention to reduce the time interval between hospital entry and emergency coronary angiography in patients with ST-elevation myocardial infarction. Isr Med Assoc J. 2017; 19: 547-552.

15 Jaffe R, Karkabi B, Goldenberg I, et al. Avoidance of coronary angiography in high-risk patients with acute coronary syndromes: the ACSIS registry findings. Cardiovasc Revasc Med. 2019 Dec 20. [Epub ahead of print]. 